\title{
Acceptance of Contraceptive Methods Among Postpartum Women in a Tertiary Care Center
}

\author{
Charusheela Kashyap $^{1} \cdot$ Ipseeta Ray Mohanty $^{1} \cdot$ Pratima Thamke $^{2} \cdot$ Y. A. Deshmukh ${ }^{1}$
}

Received: 6 April 2016/Accepted: 13 July 2016/Published online: 23 July 2016

(C) Federation of Obstetric \& Gynecological Societies of India 2016

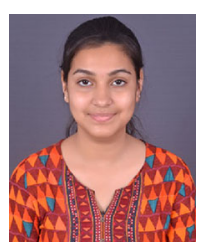

\begin{abstract}
About the Author
Charusheela Kashyap is a budding doctor, a final year MBBS student at MGM Medical College, Navi Mumbai. She has completed the following ICMR STS project successfully with approval of the report by ICMR. Charusheela is looking forward to do various research projects in the coming years of her medical education and contribute toward welfare of the society. She believes in putting in her best to do applied research in the formative years of medical education.
\end{abstract}

\begin{abstract}
Background In India, a large proportion of women with an unmet need for contraception are within their first year after childbirth. Therefore, concentrating efforts to educate
\end{abstract}

Charusheela Kashyap is a IIIrd year MBBS student at MGM Medical College; Dr. Ipseeta Ray Mohanty is a Professor of Pharmacology at Mahatma Gandhi Mission Medical College; Dr. Y. A. Deshmukh is a professor and HOD of Pharmacology at Mahatma Gandhi Mission Medical College; Dr. Pratima Thamke is a Assistant Professor of Obstetrics and Gynecology at Mahatma Gandhi Mission Medical College Hospital for Women and Children.

Ipseeta Ray Mohanty

ipseetamohanty@yahoo.co.in

1 Department of Pharmacology, Mahatma Gandhi Mission Medical College, Kamothe, Navi Mumbai, Maharashtra, India

2 Department of Obstetrics and Gynecology, Mahatma Gandhi Mission Medical College Hospital for Women and Children, Kalamboli, Navi Mumbai, Maharashtra, India postpartum women on the importance of attending contraceptive clinics could have a proportionally bigger impact on increasing postpartum contraception usage.

Methods Hundred and seventy-eight (178) women were followed up to determine the proportion of postpartum women who attended the family planning clinics for contraceptive counseling. The reason for non-attendance, choice and effectiveness of contraceptive method selected was determined.

Results Out of 178 postpartum women who were followed up, only $12(6.8 \%)$ attended the contraceptive clinic. IUD, POPs and Inj-DMPA are the preferred contraceptive methods selected by postpartum women. Hundred percent of the postpartum women who attended contraceptive selected a contraceptive method as compared to only $44 \%$ of the postpartum women who did not attend a contraceptive clinic. Only $29.2 \%$ of these postpartum women selected highly effective contraceptive methods as compared to $83.3 \%$ by the postpartum women who attended family planning clinics. The common reasons cited for not 
attending contraceptive clinic was found to be time constraint $(43.9 \%)$ followed by 'stay far away' (39\%), followed by 'already have information' $(9.7 \%)$.

Conclusions Family planning service that is scheduled to be delivered at the 6-week postpartum is rarely attended. The common reason cited by postpartum women for poor attendance in these family planning clinics was time constraint.

Keywords Contraception · Postpartum - Counseling · Contraceptive clinics

\section{Introduction}

Recent Indian National Family Health Survey (NFHS) data show that the chances of infant and maternal survival would be 2.5 times as high with birth intervals of 3-5 years as with intervals of two or fewer years $[1,2]$. In this context, the postpartum period is particularly important. Perhaps the most important concern is that contraceptive use is no more than $17 \%$ among the women immediately and within 6 months postpartum and around $33 \%$ between 6 and 12 months after delivery [3, 4]. Most women are at risk of unintended pregnancy in the postpartum and extended postpartum period [3].

Given the growing evidence that short inter-pregnancy intervals increase the risk of infant and maternal mortality and morbidity, postpartum family planning should be considered as a life-saving intervention $[5,6]$. To avoid the adverse outcomes associated with closely spaced births, medical guidelines recommend the uptake of a family planning method by 6 weeks postpartum. Protocols to implement these recommendations have been adopted around the world since the 1960s and are still not well in place today [7]. Therefore, various interventions to improve contraceptive usage among postpartum women are warranted.

There are studies which conclusively prove the benefits of counseling on the contraceptive acceptance among postpartum women [8-11]. However, many postpartum women are denied the benefits of contraception because of non-attendance to contraceptive clinics. Therefore, there is an urgent need to identify the proportion of women seeking and accepting contraceptive advice in the hospital set up. The study also intends to identify the reasons for nonattendance among the postpartum women in spite of a schedule contraceptive visit. Such information will help in planning preventive interventions wherever possible to reinforce the acceptance of contraceptive methods among postpartum women. With this background, the present study has been designed. It may be postulated that when women get the right message after child birth, there is high likelihood that they will take on an family planning method so as to either delay a pregnancy or completely stop child birth.

\section{Methodology}

Necessary approval from the Institutional Ethics Committee was obtained before initiating the study. The study was a cross-sectional, interventional study conducted among postpartum women who conformed to the specified inclusion and exclusion criteria

Inclusion criteria:

- Postpartum women within 10 weeks of delivery seeking contraceptive advice

- Women opting for immediate postpartum IUD

- Postpartum women opting for permanent method of sterilization

- Women who agree to sign an informed consent form

Exclusion criteria:

- Postpartum women more than 10 weeks post-delivery

- Women who do not agree to sign an informed consent form

\section{Study Procedure}

The deliveries $6-10$ weeks retrospectively from the period May 2015 to June 2015 were noted from the hospital records. Information regarding those women who had undergone permanent method of sterilization or had IUD inserted immediately postpartum was recorded. The proportion of postpartum women attending the obstetrics and gynecology OPD seeking contraceptive advice within 10 weeks of delivery was noted. These postpartum women were counseled by the medical student under the supervision of the gynecologist. Subsequently, they were asked to fill a questionnaire (Part A) specially designed for the study about contraceptive usage and their choice of contraceptive method post-contraceptive advice. The postpartum women who did not turn up to attend the contraceptive clinic were contacted telephonically to find out the reasons behind their decision. Their views were noted down on the study questionnaire (B).

\section{Effectiveness of Contraceptive Methods}

Contraceptive effectiveness was categorized as

- Highly effective $(<10 \%$ of women experience an unintended pregnancy; includes sterilization, intrauterine device, contraceptive pill, transdermal patch and vaginal ring) 
Fig. 1 Disposition summary of women

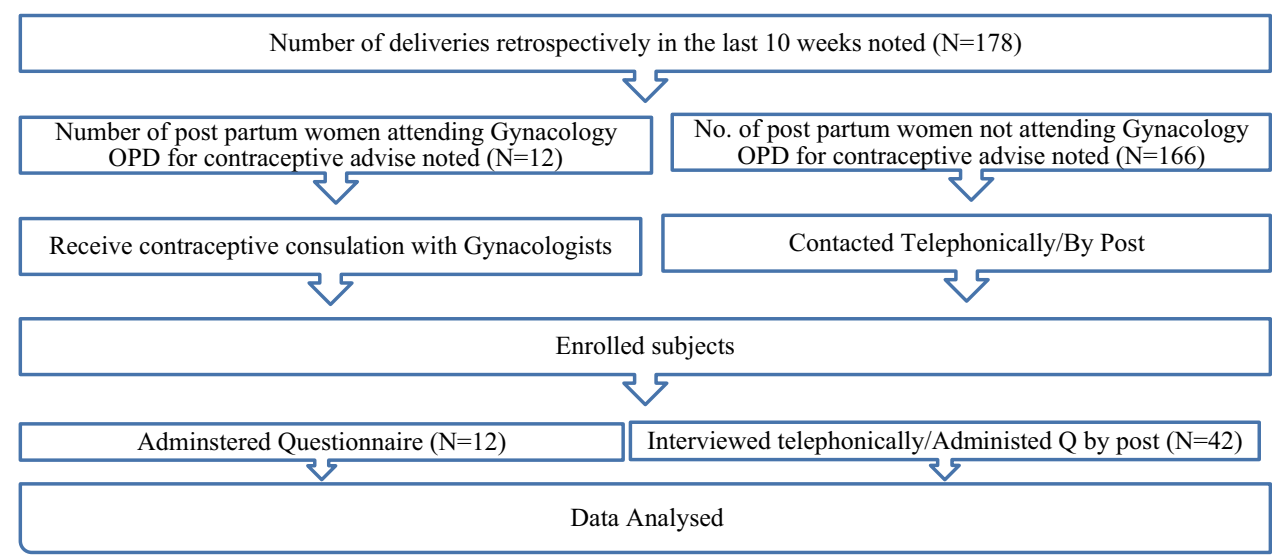

- Moderately effective (10-15\% failure rate; includes condoms)

- Less effective $(>15 \%$ failure rate; includes diaphragm, cervical cap, sponge, rhythm and withdrawal).

\section{Observations and Results}

\section{Disposition Summary of Postpartum Women}

Hundred and seventy-eight (178) women were followed up to determine the proportion of postpartum women who attended the contraceptive clinics for contraceptive counseling (Fig. 1).

\section{Demographical Data of Postpartum Women}

Out of the postpartum women enrolled for the study, $54.5 \%$ women were of the age group 21-25 (Fig. 2). $68.6 \%$ had a normal delivery compared to $31.4 \%$ who had to undergo a caesarian section. Out of 178 postpartum women who were followed up, only $12(6.8 \%)$ attended the contraceptive clinic. Majority of the postpartum women $(93.2 \%)$ did not attend contraceptive clinic (Fig. 2).

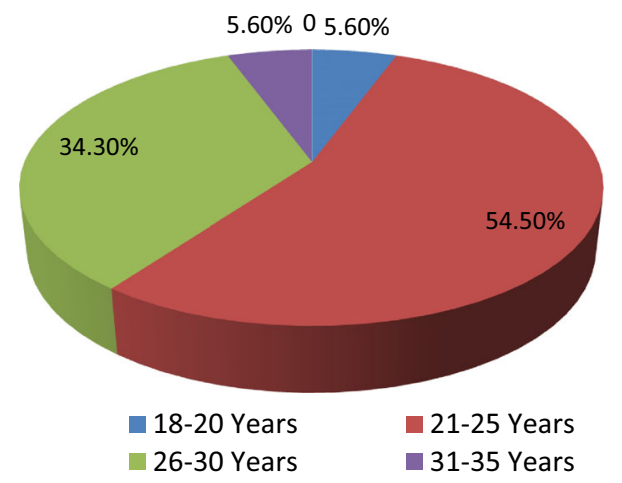

Fig. 2 Age distribution among postpartum women $(N=178)$

\section{Characteristics of Postpartum Women Attending Contraceptive Clinics}

$91.6 \%$ of the 12 postpartum women who attended contraceptive clinic felt that the contraceptive counseling was very effective. Majority (41.6\%) of these women selected POP as their choice of contraceptive method. Interestingly, $83.3 \%$ of these postpartum selected highly effective contraceptive methods (Table 1).

\section{Characteristics of Postpartum Women Not Attending Contraceptive Clinics}

$56.1 \%$ of the postpartum women not attending contraceptive clinics had not selected any contraceptive method (Table 2). The common reasons cited for not attending contraceptive clinic was found to be 'have no time' (43.9\%) followed by 'stay far away' (39\%), followed by 'already have information' (9.7\%) (Fig. 3).

\section{Comparison of Contraceptive Methods and Effectiveness of Contraceptive Method Selected Among Both the Groups}

Hundred percent of the postpartum women who attended contraceptive clinic selected a contraceptive method as compared to only $44 \%$ of the postpartum women who did not attend a contraceptive clinic (Fig. 4). Only $29.2 \%$ of these postpartum women selected highly effective contraceptive methods compared to $83.3 \%$ by the postpartum women who attended contraceptive clinics (Fig. 5).

\section{Discussion}

A large number of pregnancies in India are unintended and associated with inadequate birth spacing. The postpartum period is an important, yet underutilized, time to initiate contraception. Evidence shows that closely spaced 
Table 1 Characteristics of postpartum women attending contraceptive clinic $(n=12)$

\begin{tabular}{|c|c|c|c|}
\hline $\begin{array}{l}\text { S. } \\
\text { no. }\end{array}$ & Characteristics & Number & Percentage \\
\hline \multirow[t]{5}{*}{1.} & Age & & \\
\hline & $18-20$ & 3 & 25 \\
\hline & $21-25$ & 6 & 50 \\
\hline & $26-30$ & 2 & 16.6 \\
\hline & $31-35$ & 1 & 8.3 \\
\hline \multirow[t]{3}{*}{2.} & Mode of delivery & & \\
\hline & Normal delivery & 11 & 91.6 \\
\hline & Caesarian section & 1 & 8.3 \\
\hline \multirow[t]{6}{*}{3.} & Education & & \\
\hline & Uneducated & 0 & 0 \\
\hline & Less than 10th pass & 5 & 41.6 \\
\hline & 12th pass & 4 & 33.3 \\
\hline & Graduate & 3 & 25 \\
\hline & Postgraduate & 0 & 0 \\
\hline \multirow[t]{3}{*}{4.} & Employment status & & \\
\hline & Employed & 1 & 8.3 \\
\hline & Unemployed & 11 & 91.6 \\
\hline \multirow[t]{4}{*}{5.} & No. of children & & \\
\hline & One & 7 & 58 \\
\hline & Two & 4 & 33 \\
\hline & Three and more & 1 & 8.3 \\
\hline \multirow[t]{4}{*}{6.} & Breast feeding status & & \\
\hline & Breast feeding & 12 & 100 \\
\hline & Exclusive breast feeding & 10 & 83 \\
\hline & $\begin{array}{l}\text { Awareness about lactational } \\
\text { amenorrhea method }\end{array}$ & 4 & 33.3 \\
\hline
\end{tabular}

pregnancies pose health risks to mothers and newborns [12]. Also, women with short inter-pregnancy intervals were at higher risk of maternal death, premature rupture of membranes and anemia [13, 14].National-level surveys: NFHS-3 data (2005-2006) show that among married women aged $15-34$, only $20 \%$ were using any contraceptive method for spacing. Therefore, postpartum contraception is vital to the reduction of short interval pregnancies, which is a significant source of neonatal morbidity and medical care costs $[1,11,15]$.

To avoid the adverse outcomes associated with closely spaced births, medical guidelines recommend the uptake of a family planning method by 6 weeks postpartum [16]. The variety of contraceptive methods available for postpartum women includes hormonal contraception (POP, InjDMPA), intrauterine devise, lactational amenorrhea, barrier contraception, natural family planning and sterilization [17]. Several studies have reported the need and utilization of contraceptives in India [4, 8]. Few studies have evaluated the impact of contraceptive counseling on the
Table 2 Characteristics of postpartum women who did not attend contraceptive clinic $(n=41)$

\begin{tabular}{|c|c|c|c|}
\hline $\begin{array}{l}\text { S. } \\
\text { no. }\end{array}$ & Characteristics $(N=41)$ & Number & Percentage \\
\hline \multirow[t]{5}{*}{1.} & Age & & \\
\hline & $18-20$ & 9 & 21.9 \\
\hline & $21-25$ & 16 & 39.02 \\
\hline & $26-30$ & 13 & 31.7 \\
\hline & $31-35$ & 3 & 7.3 \\
\hline \multirow[t]{3}{*}{2.} & Mode of delivery & & \\
\hline & Normal delivery & 38 & 92.6 \\
\hline & Caesarian section & 3 & 7.4 \\
\hline \multirow[t]{5}{*}{3.} & Education status & & \\
\hline & Uneducated & 4 & 9.7 \\
\hline & Less than 10th pass & 19 & 46.3 \\
\hline & 12th pass & 12 & 29.3 \\
\hline & Graduate & 6 & 14.6 \\
\hline \multirow[t]{3}{*}{4.} & Employment status & & \\
\hline & Employed & 6 & 14.6 \\
\hline & Unemployed & 35 & 85.4 \\
\hline \multirow[t]{4}{*}{5.} & No. of children & & \\
\hline & One & 19 & 46.3 \\
\hline & Two & 19 & 46.3 \\
\hline & Three and more & 3 & 7.3 \\
\hline \multirow[t]{4}{*}{6.} & Breast feeding status & & \\
\hline & Breast feeding & 41 & 100 \\
\hline & Exclusive breast feeding & 17 & 41.5 \\
\hline & $\begin{array}{l}\text { Awareness about lactational } \\
\text { amenorrhea method }\end{array}$ & 7 & 17.1 \\
\hline
\end{tabular}

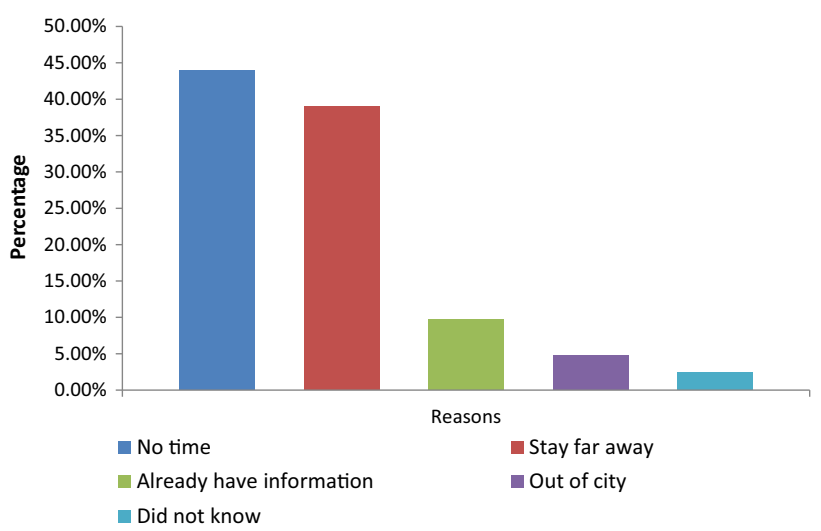

Fig. 3 Reasons for not attending contraceptive clinic cited by postpartum women

selection, of contraceptive methods among postpartum women. A study conducted by Goel et al. [18] shows that women who received advice on family planning were more likely to adopt postpartum contraception (unadjusted OR $1.63, P<0.001)$ than those who were not advised at all. 


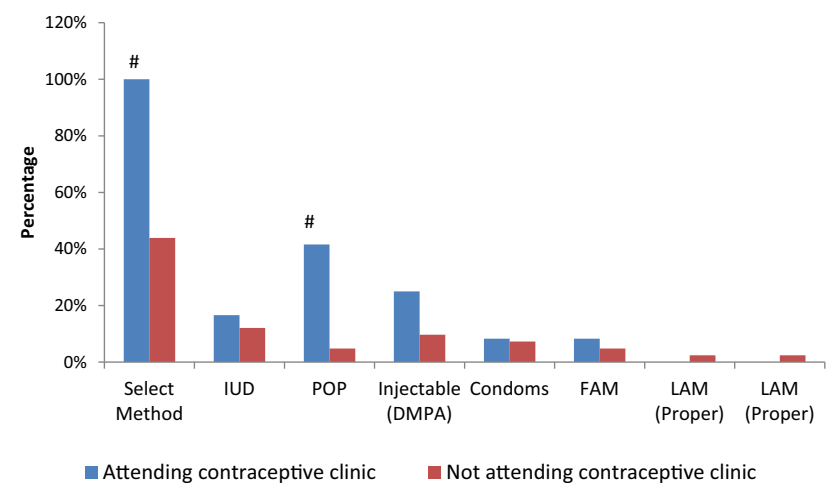

Fig. 4 Contraceptive method selected among postpartum women. ${ }^{\#} P<0.05$ postpartum women attending versus not attending contraceptive clinics: IUD intrauterine devise, $P O P$ progesterone only pill, FAM fertility awareness method, LAM lactational amenorrhea method

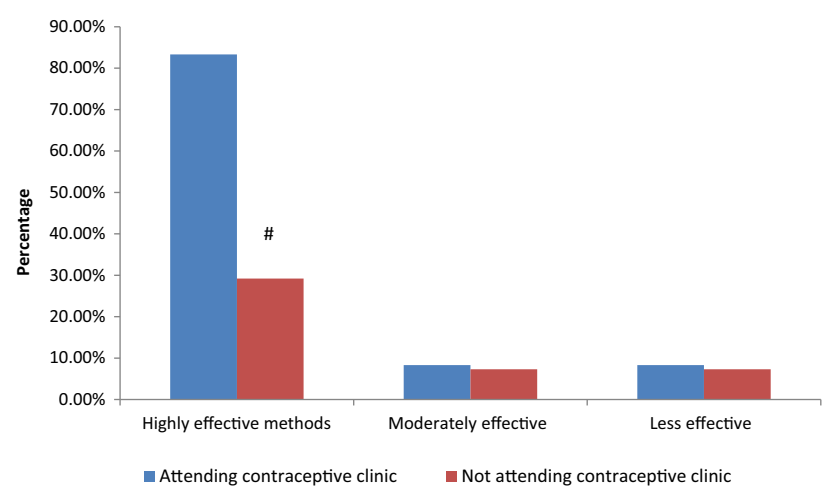

Fig. 5 Comparative effectiveness of contraceptive method selected. ${ }^{\#} P<0.05$ postpartum women attending versus not attending contraceptive clinics

Similar findings have been reported by studies conducted by Chabbra et al. [19]. However, very few postpartum women are attending the contraceptive clinics and availing the facility of contraceptive counseling because of which they are denied the benefits of these counseling sessions [16]. There are no baseline data available in India on the proportion of postpartum women who come back to the hospital to attend contraceptive clinics. More importantly, the reasons for the poor turnover are also not determined. Such information may be very vital to plan interventions wherever possible at all levels so as to increase contraceptive acceptance among postpartum women.

The present study was the first of its kind as it provided a complete perspective on the proportion of postpartum women who seek contraceptive counseling and accept a contraceptive method. The present study demonstrated that only $6.8 \%$ of the postpartum women actually attended contraceptive clinics in spite of a scheduled visit. Rossier et al. compiled data from the five centers in Sub-Saharan Africa. A great variation across centers, with attendance rates in contraceptive clinics ranging from 4 to $33 \%$, was observed. The health staff acknowledged that low attendance at the 6-week checkup visit was an ongoing problem [16]. The results of the present study show that 6-week follow-up visit as the occasion to offer family planning services is not very effective. It is difficult to motivate women to come back to health centers for family planning at a time when most of them do not yet need it. Placing a first family planning visit before women's discharge after a delivery could be perhaps much more effective in reaching all women.

Majority of these postpartum women (91\%) found the counseling sessions very effective. Interestingly, attending contraceptive clinics significantly impacted the acceptance of contraceptive, as evident by difference in proportion of postpartum women accepting a contraceptive method between those attending compared to those not attending (100 vs $44 \%$ ) contraceptive clinics. Additionally, availing the family planning uptake services resulted in selection of a more effective contraceptive method ( $83 \%$ ) as compared to that seen among those not attending the contraceptive clinics $(23 \%)$.

In the present study, overall, the POP, IUD and InjDMPA injections were found to be the preferred contraceptive method selected by postpartum women. This is in conformity with the results for India in the world contraceptive use pattern survey [18]. Interestingly, although majority of postpartum women were practicing breast feeding, $50 \%$ of the postpartum women were not exclusively breast feeding and following the criteria of lactational amenorrhea method (LAM) of contraception. Ironically, only $20 \%$ of the postpartum women were actually aware of LAM as an effective contraceptive method. Similar to the present results, a study result conducted by Fabic et al. shows that majority of women did not seem to know that amenorrhea alone would not protect a woman from pregnancy. There is a need to raise awareness of LAM and persuade women to either follow the LAM criteria or use another method of contraception [20-22].

Uptake of a contraceptive method (100\%) and choice of highly effective contraceptive method $(83 \%)$ were high among women who attended clinic for contraceptive advice in the immediate postnatal period. However, the pressing concern remains that majority (93\%) of postpartum women did not attend these contraceptive clinics and were perhaps deprived of the benefits of a balanced contraceptive guidance. Therefore, it is important to understand and determine the reasons for the poor turn out at contraceptive clinics so that appropriate interventions can be planned at all levels. The common reasons cited for not attending contraceptive clinic among postpartum women was 'have no time' (43.9\%) followed by 'stay far 
away' (39\%), followed by 'already have information' $(9.7 \%)$.

It is important to highlight that although these postpartum women did not attend the contraceptive clinics, interestingly they came to the same hospital to avail facilities of other clinics: postnatal checkup (29.2\%) and immunization clinics $(58.5 \%)$. It may thus be postulated that providing family planning information and/or services to postpartum women during their infants' immunization visits or their postnatal checkup may be an effective way to reach women with high unmet need for family planning. At the same time, it is important to involve family members in the counseling process so that they help the postpartum women to 'find time' and keep such important appointments with the contraceptive clinics.

In many societies, including India, men are seen as decision-makers in matters related to contraception. With their power to decide, they need to be involved in making contraceptive decisions. Contraceptive uptake may be increased by joint decision-making, and this aspect is important, especially during counseling sessions. Joint decision-making may imply good relational and spousal communication perhaps impacting the attendance in clinics as well as getting translated into increased contraceptive usage. Recently, the role of task shifting (from physicians to health workers and para medicals) to expand the accessibility to family planning methods has been emphasized. Hence, appropriate training and guidelines should be provided for dissemination of family planning methods and as well as optimization of the resources in health centers [23].

Besides the cited reasons, the poor uptake of family planning services may be linked to the low education status of the postpartum women. Only $16 \%$ of the postpartum women surveyed were graduates. This may partly explain the poor accessibility and information among these postpartum women regarding the various available family planning services and importance of adopting contraceptive methods. A study conducted by Prusty [24] has reported that in Jharkhand, only $15 \%$ tribal women without any education used modern contraceptives compared to $35 \%$ of women with 10 or more years of education. Communication intervention has therefore the potential to increase uptake of family planning services.

Though the study has significant findings, limitation of the study includes no follow-up visit to assess participant's actual choice and compliance and no direct involvement of male partners in counseling. The strengths of this study were the use of a unique standard structured counseling material for counseling. In addition, the study has provided baseline information on the attendance in contraceptive clinics, contraceptive usage and effectiveness of the method chosen among postpartum women. The study will also provide lead for reasons for poor turn out for family planning services so that appropriate interventions can be planned to promote contraception usage.

\section{Conclusions}

Family planning service that is scheduled to be delivered at the 6-week postpartum is rarely attended. Only $6.8 \%$ of the postpartum women attend these contraceptive clinics. The common reasons cited by postpartum women for poor attendance in these family planning clinics was time constraint, followed by distance from home. IUD, POPs and Inj-DMPA are the preferred contraceptive methods selected by postpartum women.

Acknowledgments The Project was an Indian Council of Medical Research-Student Stewardship program 2015 Project (Ref No. 2015-00482).

\section{Compliance with Ethical Standards}

Conflict of Interest The authors declare that there is no conflict of interest.

Ethical Statements All procedures performed in studies involving human participants were in accordance with the ethical standards of the institutional and/or national research committee and with the 1964 Helsinki declaration and its later amendments or comparable ethical standards.

\section{References}

1. International Institute for Population Sciences (IIPS) and Macro International, National Family Health Survey (NFHS-3), 2005-06. India, Vol. 1. Mumbai: IIPS; 2007.

2. Shah IH, Say L. Maternal mortality and maternity care from 1990 to 2005: uneven but important gains. Reprod Health Matters. 2007;15(30):17-27.

3. Vernon R. Meeting the family planning needs of postpartum women. Stud Fam Plann. 2009;40(3):235-45.

4. Sebastian MP, Khan ME, Kumari K, et al. Increasing postpartum contraception in rural India: evaluation of a community-based behavior change communication intervention. Int Perspect Sex Reprod Health. 2012;38(2):68-77.

5. DaVanzo J, Hale L, Razzaque A, et al. Effects of interpregnancy interval and outcome of the preceding pregnancy on pregnancy outcomes in Matlab, Bangladesh. $\mathrm{Br} \mathrm{J}$ Obstet Gynaecol. 2007;114(9):1079-87.

6. Rutstein SO, Further evidence of the effects of preceding birth intervals on neonatal, infant and under-five-years mortality and nutritional status in developing countries: evidence from the Demographic and Health Surveys, DHS Working Papers, No. 41. Calverton, MD, USA: Macro International; 2008.

7. World Health Organization (WHO). Programming strategies for postpartum family planning. Geneva: WHO; 2013.

8. Arora YL, Sharma GD. Family planning through post-partum communication in Dufferin Hospital, Lucknow. POPCEN News Lett. 1977;3(4):9-14. 
9. Hingorani V. Methods of birth control. Choice is yours. Yojana. 1984;28(19):33-4.

10. Machado RB, Pompei LM, Giribela A, et al. Impact of standardized information provided by gynecologists on women's choice of combined hormonal contraception. Gynecol Endocrinol. 2013;29(9):855-8.

11. Sheriar N, Joshi R, Mukherjee B, et al. Impact of counseling on selection of hormonal contraceptive among Indian women. In: 18 th world congress on controversies in obstetrics, gynecology \& infertility. Vienna, Austria, 2013; 24-27:57.

12. Smith R, Ashford L, Gribble J, et al. Family planning saves lives. Washington, DC: Population Reference Bureau; 2009.

13. Conde-Agudelo A, Belizan JM. Maternal morbidity and mortality associated with inter-pregnancy interval: cross sectional study. $\mathrm{Br}$ Med J. 2000;321(7271):1255-9.

14. Collumbien M, Gerressu M, Cleland J. Non-use and use of ineffective methods of contraception. In: Ezzati M, Lopez AD, Rodgers A, Murray CJL, editors. Comparative quantification of health risks: Global and regional burden of disease attributable to selected major risk factors. Geneva: World Health Organization, Chapter 2004; 15:1255-1320.

15. Lete I, Doval JL, Perez-Campos E, et al. Factors affecting women's selection of a combined hormonal contraceptive method: the TEAM-06 Spanish -sectional study. Contraception. 2007;76:77-83.

16. Rossier C, Hellen J. Traditional birth spacing practices and uptake of family planning during the postpartum period in Ouagadougou: qualitative Results. Int Perspect Sex Reprod Health. 2014;40(2):87-94.
17. Baveja R, Buckshee K, Das K, et al. Evaluating contraceptive choice through the method-mix approach. An Indian Council of Medical Research (ICMR) task force study. Contraception. 2000;61:113-9.

18. Goel S, Bhatnagar I, Khan ME, et al. Increasing postpartum contraception in rural Uttar Pradesh. J Fam Welf. 2010;56:57-64.

19. Chhabra HK, Mohanty IR, Mohanty NC et al. Impact of structured counseling on choice of contraceptive method among postpartum women. J Obstet Gynecol India. 2015; 6:1-9.

20. Fabic MS, Choi Y. Measuring use of the lactational amenorrhea method through the Demographic and Health Surveys: data quality and implications. In: Paper presented at the annual meeting of the Population Association of America, New Orleans, April 11-13, 2013.

21. Lactational Amenorrhea method. Expanding contraceptive use in urban Uttar Pradesh: lactational amenorrhea method (LAM), (March 2010). www.uhi-india.org.

22. Kunwar S, Faridi MM, Singh S, et al. Pattern and determinants of breast feeding and contraceptive practices among mothers within six months postpartum. Biosci Trends. 2010;4(4):186-9.

23. Polus S, Lewin S, Glenton C, et al. Optimizing the delivery of contraceptives in low- and middle-income countries through task shifting: a systematic review of effectiveness and safety. Reprod Health. 2015;12(1):27.

24. Prusty RK. Use of contraceptives and unmet need for family planning among tribal women in india and selected hilly states. J Health Popul Nutr. 2014;32(2):342-55. 